\title{
Influence of smoking and packaging methods on physicochemical and microbiological quality of smoked mackerel (Scomber scombrus)
}

\author{
Peter Popelka ${ }^{1}$, Monika Šuleková ${ }^{1}$, Pavlína Jevinová ${ }^{1}$, Boris Semjon ${ }^{1}$, Terézia Hudáková ${ }^{2}$ \\ Tatiana Klempová ${ }^{3}$, Milan Čertík ${ }^{3}$, Pavol Roba ${ }^{1}$, Matúš Várady ${ }^{1}$ \\ ${ }^{1}$ University of Veterinary Medicine and Pharmacy in Košice, Košice, Slovakia \\ ${ }^{2}$ Pavol Jozef Šafárik University in Košice, Faculty of Medicine, Košice, Slovakia \\ ${ }^{3}$ Slovak University of Technology in Bratislava, Faculty of Chemical and Food Technology, Bratislava, Slovakia
}

Received February 17, 2020

Accepted February 24, 2021

\begin{abstract}
Flesh and fatty acid compositions, total volatile basic nitrogen (TVB-N), lipid oxidation and aerobic plate count, Enterobacteriaceae, psychrotrophic bacteria were determined in raw and smoked mackerel during cold storage (three groups differing in way of packaging; unpacked (UP), vacuum packaging (VP) and modified atmosphere (MAP) at 7, 14, 21, 28, 35, and 42 days. The protein, fat content and $\mathrm{n}-3$ polyunsaturated fatty acids increased after smoking. The $\mathrm{pH}$ value and TVB-N were significantly higher in unpacked mackerel. Initial malondialdehyde concentration in raw mackerel was lowered after smoking and then lipid oxidation was the most pronounced in unpacked mackerel. Hot smoking, vacuum packaging, and modified atmosphere reduced bacterial growth, while the microbial contamination in all groups was below the limits during the whole period of storage. However, physicochemical properties of unpacked mackerel exceeded the limits from day $35 \mathrm{on}$. The present study indicates a lowering of products of secondary lipid oxidation after smoking followed by accelerated lipid degradation during cold storage of unpacked smoked mackerel. It is suggested that the smoking process and appropriate packaging method can protect lipids as well as valuable polyunsaturated fatty acids from oxidation. Vacuum packaging and modified atmosphere ensured microbial quality and protein and lipid stability. Their use is recommended for extending the shelf life of smoked fish considering the initial microbial and also chemical quality before and after smoking.
\end{abstract}

Fish, smoke, vacuum packaging, modified atmosphere, cold storage

In recent years, fish consumption has been promoted as part of a healthy diet. The nutritional benefits of fish are due to the content of high quality protein, vitamins, and other essential nutrients. Fatty fish are high in two n-3 polyunsaturated fatty acids (PUFAs): eicosapentaenoic (EPA) and docosahexaenoic acid (DHA). Atlantic mackerel (Scomber scombrus) is an important source of both of them (Romotowska et al. 2016). However, in fatty species of fish, the most serious cause of deterioration is oxidation. When exposed to further oxidation conditions, products of primary lipid oxidation can generate secondary oxidation products, including aldehydes and ketones. The presence of oxidized lipids in human nutrition results in an increase of thiobarbituric acid reactive substances (TBARs) in blood and tissues expressed as the malondialdehyde (MDA) content (Barriuso et al. 2013).

Smoking is one of the most common methods of food preservation widely used also in fish processing. The composition of the smoke and the fish processing influences the sensory quality, shelf life, and safety of the product (Stołyhwo and Sikorski 2005). The smoke consists of chemicals such as phenols, organic acids, alcohols, carbonyls, and hydrocarbons. Among these components, phenols have demonstrated antioxidant capabilities (Bower et al. 2009). It has been suggested that the smoking process can protect valuable PUFA in fish oils from oxidation. 
The microflora in caught fish depends on the microbial contamination of the water and includes bacterial species such as Pseudomonas, Alcaligenes, Vibrio, Serratia and Micrococcus (Gram and Huss 2000) Microbial growth and enzymatic activity are major causes of fish spoilage when amines, biogenic amines, sulphides, aldehydes and ketones with unacceptable off-flavours are produced (Ghaly et al. 2010). The proteolytic degradation of fish proteins leads into the spoilage of fish and production of total volatile base nitrogen (TVB-N). Fish packaging is one of the methods necessary for storage, suitable distribution and maintaining nutritional and microbial quality. Vacuum packaging (VP) and modified atmosphere packaging (MAP), together with low temperature, have become popular preservation methods, which brought important changes in storage, distribution and marketing of raw fish and fishery products. Vacuum-packaging and MAP can provide improvement in fish shelf life, organoleptic quality, and product range (Koral et al. 2010).

This research investigated the flesh and fatty acid compositions, TVB-N, TBARs and aerobic plate count, Enterobacteriaceae, psychrotrophic bacteria in raw and smoked mackerel during cold storage as differing in the way of packaging: unpacked (UP), VP and MAP at 7, 14, 21, 28, 35, and 42 days of storage.

\section{Materials and Methods}

Smoking and packaging of mackerel

Frozen Atlantic mackerel (Scomber scombrus) was used for the experiment and the effect of hot smoking was investigated in the first phase. The samples for chemical and microbiological analysis were taken from thawed mackerel and immediately after smoking. Whole mackerel (350-400 g), frozen on board ship, were kept at $-20^{\circ} \mathrm{C}$ for a maximum of 4 months prior to smoking and brining. After thawing in water at $18{ }^{\circ} \mathrm{C} / 12 \mathrm{~h}$, the fish were eviscerated and immersed in a brine containing $80 \mathrm{~g} / \mathrm{l}$ salt, with a fish:brine ratio of 1:1 (w/v), for $12 \mathrm{~h}$. The smoking process was performed according to the following procedure: after dripping surface drying at $45^{\circ} \mathrm{C}$, hot smoking at $95{ }^{\circ} \mathrm{C}$ for $1 \mathrm{~h}$, and then heating at $85{ }^{\circ} \mathrm{C}$ for $20 \mathrm{~min}$. The smoked products were chilled to $2{ }^{\circ} \mathrm{C}$ and packed. The first group was packed into perforated cardboard boxes, covered with parchment paper only, the second group was packed under vacuum, and the third group was packed under modified atmosphere $(40 \%$ $\mathrm{CO}_{2} / 60 \% \mathrm{~N}_{2}$ ). Vacuum packaging and MAP packing were performed with the Multi VAC machine (A 300/16, Germany). In each package, there was only one fish. After packing, the fish were transported to the laboratory and stored at $0-4{ }^{\circ} \mathrm{C}$.

For each sampling, primarily, the meat was aseptically taken from the dorsal region of three fish to prepare the pool sample used for determination of the microbiological properties. The mackerels were minced in a meat grinder, and mixed thoroughly to prepare homogeneous sample. Then, microbiological and chemical analyses were conducted at regular intervals and in triplicate.

Chemical composition

The $\mathrm{pH}$ was measured by $\mathrm{pH} /$ Conductometer Consort C832 (Consort, Belgium), after homogenizing a $5 \mathrm{~g}$ of the muscle in $45 \mathrm{ml}$ of deionised water. Fat was determined by the Soxhlet method (AOAC 2000) in SOXTHERM S106 Automatic Extraction Unit (Gerhardt, Germany). Total nitrogen was determined by the Kjeldahl method (AOAC 2000) in Kjeldahltherm Digestion Unit and Vapodest VAP Distillation System (Gerhardt, Germany) and then converted to crude protein multiplying by 6.25 . The salt content was determined using the titration method of Volhard (ISO 1841-1).

Fatty acid composition

Fatty acids from flesh were converted into their methyl esters by modified method according to Čertík and Shimizu (2000). The methyl esters were measured with gas chromatograph (GC-6890 N, Agilent Technologies, USA) according to Gajdoš et al. (2015). The fatty acid methyl ester peaks were identified by authentic standards for a fatty acid methyl ester mixture (Supelco, USA) and quantified by an internal standard of heptadecanoic acid (C17:0, Supelco, USA). The fatty acid concentrations were evaluated with ChemStation software B0103 (Agilent Technologies, USA). All the values were expressed as results of triplicate determination.

TVB-N determination

TVB-N was determined with a Kjeltec System 2300 (Foss Tecator, USA); (AOAC 1995). TVB-N was distilled and the distillate was collected in boric acid in the presence of indicators (methyl red mixed with bromocresol green) and titrated with $0.1 \mathrm{~N}$ hydrochloric acid. The TVB-N value was expressed as mg N/100 g sample of fish flesh.

Determination of MDA by RP-HPLC

MDA was measured as a 2,4-dinitrophenylhydrazine (DNPH) derivate using high-performance liquid chromatography (HPLC) for the analysis (Reitznerová et al. 2017). The HPLC equipment was DionexUltiMate 
3000 RS equipped with diode array detector (DAD) and Chromeleon Chromatography Data System, Version 7.2 (Thermo Fisher Scientific, Germany). Separation and HPLC analysis of MDA-DNPH adduct was reached using column Polaris C18-A $(5 \mu \mathrm{m} ; 250 \times 4.6 \mathrm{~mm})$ (Varian, USA). Elution was performed isocratically with the mobile phase consisting of water, acetonitrile, and glacial acetic acid (61:39:0.2, v/v/v) at a flow rate of $1 \mathrm{ml} / \mathrm{min}$. A column heater maintained the temperature at $25^{\circ} \mathrm{C}$. The DAD was set at $307 \mathrm{~nm}$.

Microbiological analysis

Samples $(10 \mathrm{~g})$ for enumeration of the total viable count (TVC), Enterobacteriaceae, and psychrotrophic bacteria, were taken aseptically from the mackerel muscle. The initial dilution were prepared in accordance with specific rules for the preparation of fish samples (ISO 6887-3). Plate Count Agar (PCA; HiMedia, India) was used to enumerate TVC of microorganisms (ISO 4833). Violet Red Bile Glucose Agar (HiMedia, India) was used to determine Enterobacteriaceae (ISO 21528-2). The PCA was used also to determine the psychrotrophic microorganisms (ISO 17410). After incubation of inoculated Petri dishes, the numbers of characteristic colonies were enumerated, calculated and displayed in $\mathrm{CFU} / \mathrm{g}$.

Statistical evaluation

Two-way analysis of variance (ANOVA) and Tukey test for multiple comparison of means with a confidence interval set at $95 \%$ was conducted with $\mathrm{R}$ - statistics software (R Core Team 2017). As the main factor, the storage period and packaging method were set according to Semjon et al. (2018).

\section{Results}

The effect of smoking on chemical and fatty acids compositions

The chemical compositions of raw and smoked mackerel are shown in Table 1. The significant reduction in moisture content and differences in chemical composition correlate with the smoked mackerel's calculated yield of $78 \%$, mainly due to dehydration. An additional effect of smoke was found in a significant decrease of the MDA content in smoked mackerel. TBARs values of non-smoked samples were significantly $(P<0.05)$ higher than the corresponding values of smoked samples. There was no significant difference $(P>0.05)$ in TVB-N in smoked mackerel compared to thawed mackerel.

Table 1. The effect of smoking on the chemical composition, MDA, and TVB-N content of raw and smoked mackerel (mean $\pm \mathrm{SD})$.

\begin{tabular}{lcccc}
\hline & Protein $(\%)$ & Fat $(\%)$ & MDA (ng/kg) & TVB-N (mg N/100 g) \\
\hline Raw mackerel & $15.79 \pm 1.99$ & $22.58 \pm 1.87$ & $964.57 \pm 130.9^{\mathrm{a}}$ & $8.52 \pm 1.9$ \\
Smoked mackerel & $18.20 \pm 2.33$ & $24.48 \pm 1.45$ & $655.21 \pm 119.1^{\mathrm{b}}$ & $11.92 \pm 3.6$ \\
\hline
\end{tabular}

a,b - significant differences in columns $(P<0.05)$; MDA - malondialdehyde; TVB-N - total volatile basic nitrogen

The results of fatty acid profile analysis in raw and smoked mackerel are shown in Table 2. It is noted that raw mackerel contained more saturated fatty acids (SFA) than smoked mackerel, although differences were not significant. Levels of PUFA were lower in thawed mackerel compared to smoked fish. The main n3 fatty acid (FA) was DHA (C22:6) which was significantly higher $(P<0.05)$ in smoked mackerel. Determinations indicated that DHA (C22:6, n3) was the major differentiating FA (from 14.506 to $19.070 \%$ ) due to its promoted occurrence in smoked mackerel. The two other main differentiating variables were oleic acid (C18:1), myristic (C14:0) and stearic acid (C18:0) due to their decreased concentrations in smoked mackerel.

\section{Chemical changes during storage}

The $\mathrm{pH}$ values are shown in Table 3. By comparing the $\mathrm{pH}$ values within the tested groups over 42 days of storage, in the UP group the $\mathrm{pH}$ started to rise significantly $(P<0.05)$ from day 28 of the experiment and then increased non-significantly up to day 42 . 
Table 2. The effect of smoking on the fatty acid profile (\%) in raw and smoked mackerel (mean \pm SD).

\begin{tabular}{|c|c|c|}
\hline Fatty acids & Raw mackerel & Smoked mackerel \\
\hline Lauric acid, C12:0 & $0.08 \pm 0.00$ & $0.07 \pm 0.01$ \\
\hline Myristic acid, C14:0 & $9.85 \pm 0.27$ & $8.94 \pm 1.18$ \\
\hline Palmitic acid, C16:0 & $17.73 \pm 0.21$ & $18.48 \pm 0.58$ \\
\hline Palmitoleic acid, C16:1-7c & $0.36 \pm 0.01$ & $0.34 \pm 0.016$ \\
\hline Palmitoleic acid, C16:1-9c & $4.89 \pm 0.08$ & $4.99 \pm 0.69$ \\
\hline Stearic acid, C18:0 & $3.89 \pm 0.07$ & $3.50 \pm 0.30$ \\
\hline Oleic acid, C18:1-9c & $14.09 \pm 0.32^{\mathrm{a}}$ & $11.65 \pm 0.99^{\mathrm{b}}$ \\
\hline Vaccenic acid, C18:1-11c & $2.79 \pm 0.04$ & $2.46 \pm 0.07$ \\
\hline Linoleic acid, C18:2-9c, 12c & $3.10 \pm 0.04$ & $2.75 \pm 0.16$ \\
\hline Gamma-linolenic acid, C18:3-6c, 9c, 12c & $0.29 \pm 0.00$ & $0.30 \pm 0.02$ \\
\hline Alpha-linolenic acid, C18:3-9c, 12c, 15c & $2.42 \pm 0.01$ & $2.46 \pm 0.26$ \\
\hline Stearidonic acid, C18:4-6c, 9c, 12c, 15c & $7.49 \pm 0.03$ & $6.35 \pm 1.05$ \\
\hline $\mathrm{C} 20: 0$ & $0.37 \pm 0.01$ & $0.30 \pm 0.02$ \\
\hline $\mathrm{C} 20: 1-11 \mathrm{c}$ & $1.31 \pm 0.08$ & $1.06 \pm 0.23$ \\
\hline $\mathrm{C} 20: 2-11 \mathrm{c}, 14 \mathrm{c}$ & $0.42 \pm 0.01$ & $0.41 \pm 0.05$ \\
\hline Dihomo-gamma-linolenic acid, C20:3-8c, 11c, 14c & $0.19 \pm 0.00$ & $0.19 \pm 0.01$ \\
\hline Arachidonic acid, C20:4-5c, 8c, 11c, 14c & $0.99 \pm 0.04^{\mathrm{a}}$ & $0.76 \pm 0.14^{\mathrm{b}}$ \\
\hline $\mathrm{C} 20: 3-11 \mathrm{c}, 14 \mathrm{c}, 17 \mathrm{c}$ & $0.31 \pm 0.01$ & $0.27 \pm 0.01$ \\
\hline Eicosatetraenoic acid, C20:4-8c, 11c, 14c, 17c, n3 & $1.60 \pm 0.02$ & $1.57 \pm 0.12$ \\
\hline Eicosapentaenoic acid, C20:5-5c, 8c, 11c, 14c, 17c & $10.04 \pm 0.22$ & $10.79 \pm 0.16$ \\
\hline $\mathrm{C} 22: 4-7 \mathrm{c}, 10 \mathrm{c}, 13 \mathrm{c}, 16 \mathrm{c}$ & $0.76 \pm 0.01$ & $0.70 \pm 0.08$ \\
\hline Docosapentaenoic acid, C22:5-4c, 7c, 10c, 13c, 16c & $0.47 \pm 0.01$ & $0.44 \pm 0.08$ \\
\hline Docosapentaenoic acid, C22:5-7c, 10c, 13c, 16c, 19c & $2.08 \pm 0.04$ & $2.15 \pm 0.05$ \\
\hline Docosahexaenoic acid, C22:6-4c, 7c,10c,13c, 16c,19c & $14.51 \pm 0.48^{\mathrm{a}}$ & $19.07 \pm 3.62^{\mathrm{b}}$ \\
\hline$\overline{\sum S F A}$ & $31.92 \pm 0.42$ & $31.29 \pm 0.44$ \\
\hline$\sum$ MUFA & $23.45 \pm 0.39$ & $20.50 \pm 1.56$ \\
\hline$\sum$ PUFA & $44.64 \pm 0.68$ & $48.21 \pm 1.97$ \\
\hline$\sum \mathrm{n}-3$ PUFA & $38.43 \pm 0.65$ & $42.66 \pm 2.06$ \\
\hline$\sum \mathrm{n}-6$ PUFA & $6.21 \pm 0.04$ & $5.56 \pm 0.09$ \\
\hline
\end{tabular}

a,b - significant differences in rows $(P<0.05)$; SFA - saturated fatty acids; MUFA - monounsaturated fatty acids; PUFA - polyunsaturated fatty acids

In the VP and MAP groups, the differences in values were non-significant throughout the storage period $(P>0.05)$.

The results of TVB-N determination are shown in Table 3. The TVB-N values were significantly higher $(P<0.05)$ in the UP group compared to groups VP and MAP from day 35 of storage. Significant differences between groups VP and MAP were not found. Based on the TVB-N concentrations in samples of a UP mackerel at 42 days, they did not meet the limit values and therefore were deemed unsuitable for human consumption.

The results of TBARs, expressed as MDA determination are shown in Table 3. By comparing the results it was found that from day 7, MDA values were significantly $(P<0.05)$ higher in UP compared to VP and MAP. From day 35 of storage significant differences $(P<0.05)$ persisted between groups UP and VP, and between groups UP and MAP, but between groups VP and MAP the differences were not significant. Since day 35 , UP mackerel did not meet the limit values and was therefore deemed unsuitable for 


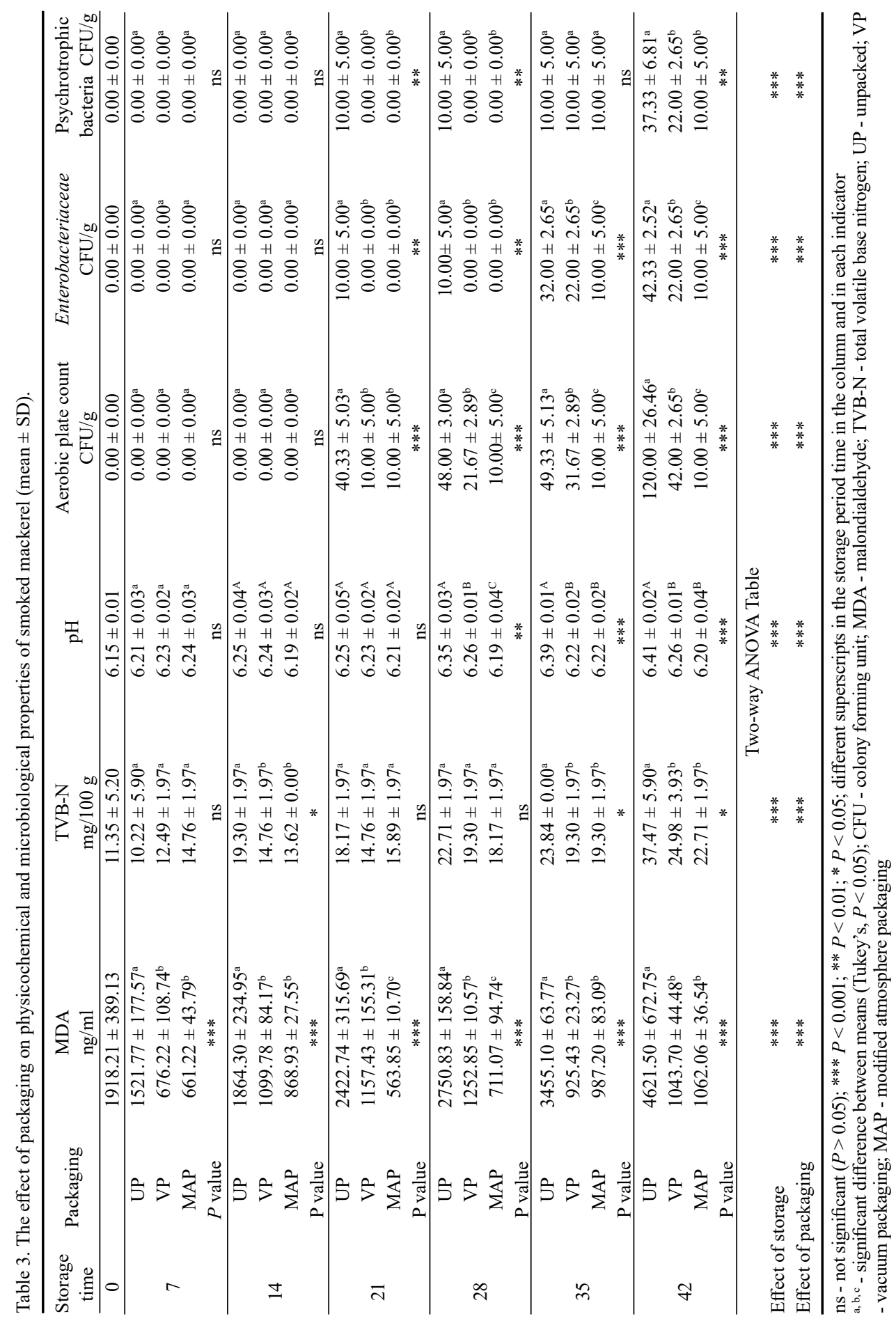


human consumption. Conversely, samples of smoked mackerel from groups VP and MAP contained an amount of MDA below the limit up to the end of storage, i.e. day 42 of the trial.

\section{Microbial changes during storage}

The results of determination of microbiological properties of raw and smoked mackerel using different types of packaging are shown in Table 3 . The low bacterial count indicates a high initial quality of the raw mackerel used for smoking. After smoking, a decline in TVC to the limit of detection was observed. During the storage of packaged smoked fish, there was an increase of TVC in group UP from day 28 of storage and high microbial growth was evident up to the end of storage. An increase of TVC was observed also in the VP group, but lower compared to the UP group. From day 35 of storage, an increase in the count of Enterobacteriaceae was evident in groups UP and VP, however, it was higher in the UP group compared to group VP. Microbial growth of psychrotrophic bacteria was found only on the last day of the storage in groups UP and VP. The highest number of bacteria was found in group UP, followed by group VP; in group MAP it remained unchanged until the experiment was completed.

\section{Discussion}

The chemical composition of wild fish depends on the sex, age, season, diet composition, migratory and reproduction changes. Food business operators are interested in knowing the chemical composition of fish as a raw material, in order to correctly apply processes of chilling, freezing, and smoking. Fish oils containing PUFA, such as EPA and DHA, are very sensitive to oxidation. The rate of oxidation is influenced by the time and temperature of chilling or freezing storage of fish before smoking, preparation of the raw material, the smoking process, and storage of the smoked products. The phenols in wood smoke are a mixture of about 240 compounds and contain mono-, di-, and trihydroxyphenols and their derivatives. The antioxidant effect of smoking has been known, since lipids in smoked mackerel do not undergo rapid oxidation. The significant decrease of the MDA content in smoked mackerel can be ascribed to the antioxidant activity of phenols in smoke absorbed by the fish during the smoking process (Goulas and Kontominas 2005). Bower et al. (2009) suggested that smoking the fish can protect valuable PUFA from oxidation and may improve their oxidative stability. Evaluating FA profile Cyprian et al. (2015) found significant changes in fish lipids when the MUFA content decreased with values corresponding to the increase in the PUFA content while SFA remained stable. Our results correlate also with the FA profile described by Stołyhwo et al. (2006) characterised by high concentrations of MUFA (35.41\%) and PUFA (32.81\%; n-3 fatty acids, 29.51\%), and a minor proportion of SFA (22.51\%).

Although the $\mathrm{pH}$ value may vary depending on the species, a lower $\mathrm{pH}$ limit of 6.2 has been established for species in a state of rest prior to sacrifice. During later postmortem stages, there is a $\mathrm{pH}$ increase due to the decomposition of nitrogenated compounds, caused primarily by microbial activity. The intensity of this $\mathrm{pH}$ change depends mainly on the storage temperature, with $\mathrm{pH}$ values above 7.1 being indicative of decomposition (Guizani and Moujahed 2015). The decrease of $\mathrm{pH}$ in the MAP group can be related to the absorption of $\mathrm{CO}_{2}$ in fish muscle. Similar results have been achieved by Love (1997) when the $\mathrm{pH}$ varied between 6.43 and 6.71. The initial TVB-N values $(10.93 \mathrm{mg} \mathrm{N} / 100 \mathrm{~g})$ are indicative of freshness of raw fish and the TVB-N content of smoked samples in the VP and MAP groups remained lower than the acceptability reported by various authors: 35-40 mg N/100 g (Connell 1990); 25-30 mg N/100 g (Lopez-Caballero et al. 2000); 20-25 mg N/100 g (Kim et al. 2002). The differences in the MDA concentration reflect 
different packaging conditions. Currently, there is no legislation available in respect to the level of oxidation in fish. According to Al-Kahtani et al. (1996), fish are acceptable for consumption at values below $3000 \mathrm{ng} \mathrm{MDA} / \mathrm{kg}$, while Ke et al. (1984) indicated that MDA values higher than $1510 \mathrm{ng} / \mathrm{kg}$ are unacceptable, and values below $576 \mathrm{ng} / \mathrm{kg}$ indicate low rates of oxidation.

The initial reduction of microorganisms is related to the effects of dehydration, antimicrobial activity of smoke components, and high temperature of hot smoking (Cyprian et al. 2015). Microbial growth in UP mackerel during storage may be due to the presence of oxygen, or succession of psychrotrophic bacteria. An increase of TVC was observed also in the VP group, but lower compared to the UP group. This could be due to the absence of oxygen, or maybe retention of antimicrobial smoke constituents that inhibited aerobic microflora growth. In the MAP group, the count of bacteria remained unchanged during the whole storage time, due to the antibacterial effect of carbon dioxide. If the aerobic counts of $<10^{5} \mathrm{CFU} / \mathrm{g}$ were to be used as a limit for consumption (ICMSF 1986; Leroi et al. 2000), all the samples including the unpacked smoked mackerel were suitable for human consumption throughout the whole storage time. The presence of Enterobacteriaceae could be a result of handling during smoking and cross contamination during storage (Shewan 2000). It can be assumed that psychrotrophic bacteria contributed to the rise of the aerobic plate count. In the MAP group, the count of bacteria remained unchanged during the whole storage time. Modified atmosphere packaging has an important role in increasing the shelf life of susceptible fish at refrigerator temperature. Usually, MAP packaging includes oxygen $\left(\mathrm{O}_{2}\right)$, carbon dioxide $\left(\mathrm{CO}_{2}\right)$, and nitrogen $\left(\mathrm{N}_{2}\right)$. Carbon dioxide, which is readily soluble in water is acting as a microbial inhibitor. Modified atmosphere packaging and VP systems could provide further improvement in the shelf life, organoleptic quality, and product range of fish (Koral et al. 2010).

Microbiological, chemical and sensory methods are used for evaluation of the freshness and quality of fish during handling and storage. Considering that the results of these analyses do not always correlate well, it is important to use all three methods for a definition of freshness of a particular species of fish.

It can be concluded that hot smoking did not cause negative changes in the fatty acid profile, conversely, the concentration of n-3 fatty acids increased. The present study also indicates a lowering of the products of secondary lipid oxidation after smoking followed by accelerated lipid degradation during the cold storage of UP smoked mackerel. Vacuum packaging and MAP ensured products' microbial quality as well protein and lipid stability and their use can be recommended for smoked fishery products considering the initial microbial and chemical quality before and after smoking. Commonly, the shelf life of smoked mackerel is specified to be between 20 to 30 days for VP and MAP. Based on our results, using MAP can maintain the quality and increase the shelf life of mackerel in cold storage conditions up to 42 days. However, the microbial contamination in all groups was below the limits during the whole period of storage; in contrast, the physicochemical properties in UP mackerel did not comply with the limits at the end of the storage time. In order to prevent the spread of microorganisms that are of public health importance, fish must be processed and stored under safe processing conditions, and physical and chemical methods should be used for quality and safety control.

\section{References}

Al-Kahtani HA, Abu-Tarboush HM, Bajaber AS, Atia M, Abou-Arab AA, El-Mojaddidi MA 1996: Chemical changes after irradiation and post-irradiation storage in tilapia and Spanish mackerel. J Food Sci 61: 729-733

AOAC 1995: Official methods of analysis. $16^{\text {th }}$ edn. Association of Official Analytical Chemists. Official methods, 985.14. Gaithersburg, MD

AOAC 2000: Horwitz W (Ed.), Official methods of analysis. $17^{\text {th }}$ edn. Association of Official Methods of Analysis Chemists, Suite, MD 
Barriuso B, Astiasarán I, Ansorena D 2013: A review of analytical methods measuring lipid oxidation status in foods: A challenging task. Eur Food Res Technol 236: 1-15

Bower CK, Hietala KA, Oliveira ACM, Wu TH 2009: stabilizing oils from smoked pink salmon (Oncorhynchus gorbuscha). J Food Sci 74: 248-257

Connell JJ 1990: Methods of assessing and selecting for quality. In Connell JJ (Ed.): Control of Fish Quality ( $3^{\text {rd }}$ edn). Fishing News Books, Oxford, UK, pp. 122-150

Cyprian OO, Van Nguyen M, Sveinsdottir K, Jonsson A, Tomasson T, Thorkelsson G, Arason S 2015: Influence of smoking and packaging methods on lipid stability and microbial quality of Capelin (Mallotus villosus) and Sardine (Sardinella gibossa). Food SciNutr 3: 404-414

Čertík M, Shimizu S 2000: Kinetic analysis of biosynthesis by an arachidonic acid-producing fungus, Mortierella alpina 1S-4. Appl Microbiol Biotechnol 54: 224-230

Gajdoš P, Nicaud JM, Rossignol T, Čertík M 2015: Single cell oil production on molasses by Yarrowia lipolytica strains over expressing DGA2 in multicopy. Appl Microbiol Biotechnol 99: 8065-8074

Ghaly AE, Dave D, Budge S, Brooks MS 2010: Fish spoilage mechanisms and preservation techniques: review. Am J Appl Sci 7: 859-877

Goulas AE, Kontominas MG 2005: Effect of salting and smoking-method on the keeping quality of chub mackerel (Scomber japonicus): biochemical and sensory attributes. Food Chem 93: 511-520

Gram L, Huss HH 2000: Fresh and processed fish and shellfish. In: Lund BM, Baird-Parker TC, Gould GW (Eds): The Microbiological Safety and Quality of Foods. Gaitherburg, Maryland, USA, Aspen Publishers Inc., pp. $472-506$

Guizani SEO, Moujahed N 2015: Seasonal variation of chemical and fatty acids composition in atlantic mackerel from the Tunisian northern-east coast. J Food Process Technol 6: 1-4

ICMSF 1986: International commission on microbiological specifications for foods. Sampling plans for fish and shellfish. In ICMSF (Ed.): Microorganisms in Foods. Sampling for Microbiological Analysis: Principles and Scientific Applications Vol. 2 ( $2^{\text {nd }}$ edn). Toronto, Canada: University of Toronto Press

ISO 1841-1 1996: Meat and meat products - Determination of chloride content - Part 1: Volhard method

ISO 17410 2001: Microbiology of food and animal feeding stuffs - Horizontal method for the enumeration of psychrotrophic microorganisms.

ISO 6887-3 2003: Microbiology of food and animal feeding stuffs - Preparation of test samples, initial suspension and decimal dilutions for microbiological examination - Part 3: Specific rules for the preparation of fish and fishery products

ISO 4833-1 2013: Microbiology of food chain. Horizontal method for the enumeration of microorganisms. Part 1: Colony count at $30^{\circ} \mathrm{C}$ by the pour plate technique

ISO 21528-2 2017 Microbiology of food and animal feeding stuffs. Horizontal methods for the detection and enumeration of Enterobacteriaceae. Part 2: Colony-count method

Ke PJ, Cervantes E, Robles-Martinez C 1984: Determination of thiobarbituric acid reactive substances (TBARS) in fish tissue by an improved distillation spectrophotometric method. J Sci Food Agric 35: 1248-1254

Kim YM, Paik HD, Lee DS 2002: Shelf-life and characteristics of fresh oysters and ground beef as affected by bacteriocin-coated plastic packaging film. J Sci Food Agric 82: 998-1002

Koral S, Sevim K, Bekir T 2010: The effect of storage temperature on the chemical and sensorial quality of hot smoked Atlantic Bonito (Sarda sarda, Bloch, 1838) packed in aluminium foil. Turk J Fish Aquat Sc 10: 439-443

Love RM 1997: Biochemical dynamics and the quality of fresh and frozen fish. In Hall GM (Ed.): Fish Processing Technology. Boston, MA, Springer, pp. 1-31

Leroi F, Joffraud J, Chevalier F 2000: Effect of salt and smoke on the microbiological quality of cold-smoked salmon during storage at $5^{\circ} \mathrm{C}$ as estimated by the factorial design method. J Food Protect 63: 502-508

Lopez-Caballero ME, Perez-Mateos M, Montero P, Borderias AJ 2000: Oyster preservation by high-pressure treatment. J Food Protect 63: 196-201

R Core Team 2017: A Language and Environment for Statistical Computing. R Foundation for Statistical Computing, Vienna, Austria

Reitznerová A, Šuleková M, Nagy J, Marcinčák S, Semjon B, Čertík M, Klempová T 2017: Lipid peroxidation process in meat and meat products: a comparison study of malondialdehyde determination between modified 2-thiobarbituric acid spectrophotometric method and reverse-phase high-performance liquid chromatography. Molecules 22:1988

Romotowska PE, Karlsdóttir MG, Gudjónsdóttir M, Kristinssona HG, Arason S 2016: Seasonal and geographical variation in the chemical composition and lipid stability of the Atlantic mackerel (Scomber scombrus) caught in Icelandic waters. J Food Compos Anal 49: 9-18

Semjon B, Král M, Pospiech M, Reitznerová A, Mal’ová J, Tremlová B, Dudriková E 2018: Application of Multiple Factor Analysis for the descriptive sensory evaluation and instrumental measurements of bryndza cheese as affected by vacuum packaging. Int J Food Prop 21: 1508-1522

Shewan JM 2000: The microbiology of sea water fish. In: Borgstrom I (Ed.): Fish as Food. Academic Press, New York, 487 p.

Stołyhwo A, Sikorski ZE 2005: Polycyclic aromatic hydrocarbons in smoked fish - a critical review. Food Chem 91: 303-311

Stołyhwo A, Kołodziejska I, Sikorski ZE 2006: Long chain polyunsaturated fatty acids in the smoked Atlantic mackerel and the Baltic sprats. Food Chem 94: 589-595 